\title{
Iron Oxide Arrays Prepared from Ferrocene- and Silsesquioxane-Containing Block Copolymers
}

\author{
Raita Goseki, Tomoyasu Hirai, Masa-aki Kakimoto, and Teruaki Hayakawa \\ Department of Organic and Polymeric Materials, Tokyo Institute of Technology, 2-12-1-S8-36 Ookayama, \\ Meguro-ku, Tokyo 152-8552, Japan \\ Correspondence should be addressed to Teruaki Hayakawa, hayakawa.t.ac@m.titech.ac.jp
}

Received 13 August 2012; Accepted 11 October 2012

Academic Editor: Maki Itoh

Copyright ( 92012 Raita Goseki et al. This is an open access article distributed under the Creative Commons Attribution License, which permits unrestricted use, distribution, and reproduction in any medium, provided the original work is properly cited.

Arrays of iron oxides as precursors of iron clusters were prepared by oxygen plasma treatment of block copolymer microphaseseparated nanostructures in thin films. Block copolymers composed of ferrocene-containing and silsesquioxane-containing polymethacrylate (PMAPOSS- $b$-PMAHFC) were successfully prepared, with different molecular weights and compositions and narrow molecular weight distributions, by living anionic polymerization. The formed microphase-separated nanostructures in the bulk were characterized by wide- and small-angle X-ray scattering (WAXS and SAXS), scanning electron microscopy (SEM), and transmission electron microscopy (TEM). Thin films were prepared from a solution of PMAPOSS- $b$-PMAHFC in tetrahydrofuran by spin coating onto silicon wafers. Fingerprint-type line nanostructures were formed in the PMAPOSS- $b$-PMAHFCs thin films after solvent annealing with carbon disulfide. Oxygen plasma treatment provided the final line arrays of iron oxides based on the formed nanostructural patterns.

\section{Introduction}

Microphase-separated nanostructures of block copolymer thin films have been studied widely because they offer simple and low-cost pattern formation on the nanometer scale. In particular, they can be used as membranes, lithography masks, and as a variety of templates for the fabrication of a variety of devices [1-7]. For the creation of unique selfassembled nanostructures and the advancement of novel functions in these applications, various block segments consisting not only of conventional organic polymers, but also of organometallic and organic-inorganic polymers have been synthesized by recently developed controlled and living polymerization methods [8-14]. The size and spacing of the microdomains can be tailored on the scale of several tens of nanometers by varying the relative molar masses of the polymer segments within the blocks and the total molar masses of the copolymers.

Carbon nanotubes (CNTs) have attracted a great deal of attention in many areas of electronics because of their exceptional electrical properties, chemical stability, and mechanical strength $[15,16]$. Among the numerous potential applications, CNTs in the form of thin films are particularly interesting for use in flexible integrated circuits [17]. CNTs properties strongly depend on the geometric arrangement of carbon atoms and the diameters of the individual tubes [18-21]. Therefore, gaining adequate control of tube diameter and geometry is essential in the protocols used for synthesizing CNTs [22-26]. One promising route to controlling the size and geometry of CNTs is a growth method using a catalytic template with iron oxides based on block copolymer thin films. Lu and coworkers have shown that iron clusters generated by reduction of iron oxides prepared from polystyrene-blockpoly(ferrocenylsilane) (PS- $b$-PFS) [22] and poly(dimethyl siloxane)-block-poly(ferrocenylsilane) (PDMS-b-PFS) [27] diblock copolymers act as an effective catalyst for the growth of CNTs. They first attempted to prepare arrays of iron oxides as precursors of iron clusters from PS- $b$ PFS thin films, but a mixture of single- and multiwalled CNTs was obtained. This was attributed to the different sizes of iron oxides generated during the high-temperature CNT growth procedure $\left(700^{\circ} \mathrm{C}\right)$. The arrays of iron oxide generated by PS- $b$-PFS thin films have low thermal stability 
because of occurring aggregation of iron oxides at the high temperature. They subsequently, improved the block copolymers in order to provide thermally and structurally stable arrays of iron oxides by using PDMS- $b$-PFS. The PDMS was able to convert to thermally stable silica that surrounded the iron structures and prevented their aggregation during CNT growth. The resulting catalytic arrays of irons provided uniform single-walled CNTs. In general, silicone-containing block copolymers can form well-ordered microphase-separated nanostructures; however, dewetting often occurs during film preparation in the PDMS-based diblock copolymer system because of its low glass transition temperatures $\left(T_{g}\right)$, below $-100^{\circ} \mathrm{C}$. This induces difficulty in forming the desired uniform thin films for producing ordered arrays of iron oxides. Therefore, a challenge remains in the preparation of silicone-containing block copolymer thin films with well-defined and stable microphase-separated nanostructures containing iron and silicon species.

We recently developed a novel series of block copolymers containing a polyhedral oligomeric silsesquioxane (POSS)containing block copolymers such as PS-block-POSS containing poly(methyl methacrylate) (PMAPOSS), PMMAblock-PMAPOSS, and poly(ethylene oxide)-block-PMAPOSS [28-32]. The PMAPOSS polymers have much higher $T_{g}$ values than that of PDMS and depend on the organic substituents of the POSS silicon atoms. They are able to stay stable and can be converted to silica using an oxidation process without dewetting. The POSS-containing block copolymers have also demonstrated good segregation during microphase separation and form much smaller periodic nanofeatures compared with many conventional block copolymers [33]. Furthermore, the etch resistance of PMAPOSS to oxygen plasma is much higher than that of polymers consisting purely of hydrocarbons, such as PEO, PMMA, and PS. Therefore, they can act not only as block copolymer lithographic materials, but also as silica thin film templates.

Herein, we report the creation of arrays of iron oxides within a silica matrix in thin films based on microphase-separated nanostructures of a series of PMAPOSS-containing block copolymers. In this study, we designed and synthesized a new PMAPOSS-containing block copolymer where one block contained a ferrocene moiety in the side chain, namely, PMAPOSS- $b$-PMAHFC. Typical examples of ferrocenecontaining side chain polymers include poly(ferrocenyl methacrylate) (PFMMA) and poly(vinyl ferrocene) (PVFC), which have relatively high $T_{g}$ values (PFMMA $T_{g}: 185^{\circ} \mathrm{C}$ ) [34-39]. In order to obtain well-ordered nanostructures in block copolymer thin films, thermal and/or solvent annealing is often necessary. However, this is not easy for polymers with high $T_{g}$ values because of the crucial annealing conditions required for reassembly of the polymer chains. Therefore, in this study, we also attempted to improve the design of the ferrocene-containing polymer to reduce its $T_{g}$ to a level suitable for forming well-ordered microphaseseparated nanostructures under mild annealing conditions. A new ferrocene-containing methacrylate monomer with an alkyl spacer (MAHFC) was synthesized and used for living anionic polymerization to create a new series of diblock copolymers, PMAPOSS- $b$-PMAHFCs. We also describe the characterization of the resulting microphaseseparated nanostructures in the bulk and thin films by small- and wide-angle X-ray scattering (SAXS and WAXS), transmission electron microscopy (TEM), and scanning electron microscopy (SEM). The oxygen plasma-treated PMAPOSS- $b$-PMAHFC thin films were then characterized by SEM and X-ray photoelectron spectroscopy (XPS).

\section{Experimental}

2.1. Materials. sec-Butyllithium (sec-BuLi) was purchased from Kanto Chemical Co. (Tokyo, Japan). 3-(3,5,7,9,11,13, 15-heptaisobutylpentacyclo-[9.5.1.3,9 $\left.1 .^{5,15} 1^{7,13}\right]$ octasiloxane -1-yl)propyl methacrylate (MAPOSS) was purchased from Hybrid Plastics Inc. (USA). The other reagents were purchased from TCI Co. (Tokyo, Japan). Prior to use, tetrahydrofuran (THF) was distilled over sodium/benzophenone in a nitrogen atmosphere until a deep purple color was achieved. MAPOSS was purified by recrystallization from methanol. 1,1-diphenylethylene (DPE) was distilled over $n$-butyllithium under reduced pressure, and lithium chloride $(\mathrm{LiCl})$ was baked under vacuum at $180^{\circ} \mathrm{C}$ for $24 \mathrm{~h}$. The other reagents were used as received.

2.2. Instrumentation and Characterization. For TEM analysis, bulk samples were embedded in epoxy resin and cured at $70^{\circ} \mathrm{C}$ for $24 \mathrm{~h}$. The embedded samples were then microtomed using a DIATOME diamond knife at room temperature to a preset thickness of $70 \mathrm{~nm}$ using Microtome. The sections were placed on TEM grids and viewed directly using a JEOL JEM-200CX at $100 \mathrm{kV}$. WAXS and SAXS measurements on the bulk samples were performed on the BL17B3 beamline at the National Synchrotron Radiation Research Center (NSRRC). Monochromatic X-ray beams of $10.5 \mathrm{keV}(\lambda=$ $1.1809 \AA)$ were used. IR spectra were recorded on a JASCO FT/IR-460 Plus spectrometer. ${ }^{1} \mathrm{H},{ }^{13} \mathrm{C}$, and ${ }^{29} \mathrm{Si}$ NMR spectra were recorded on a JEOL JNM-AL 300 spectrometer at $300 \mathrm{MHz}, 75 \mathrm{MHz}$, and $59.4 \mathrm{MHz}$, respectively. Thermal analyses of the compounds, thermogravimetric analysis (TGA), and differential scanning calorimetry (DSC) were carried out using a Seiko SSC/6000 (TG/DTA 6200 and DSC6200) thermal analyzer with ca. $5 \mathrm{mg}$ of samples at a heating rate of $10^{\circ} \mathrm{C} \mathrm{min}^{-1}$. Nitrogen was used as the purge gas at a flow rate of $50 \mathrm{~mL} \mathrm{~min}^{-1}$ for both the TGA and DSC measurements. Size-exclusion chromatography (SEC) measurements were carried out using a Shodex GPC-101, two columns (Shodex KF-802 and Shodex KF-806 M), and a Shodex RI-71 detector. THF was used as the eluent with

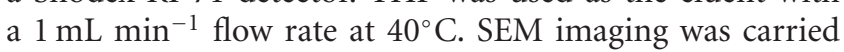
out using a Hitachi S-4800 SEM with a field-emission source at $1.0 \mathrm{kV}$. XPS was carried out using AlK $\alpha$ radiation $(h \nu=$ $1486.6 \mathrm{eV}$ ) as the photo source and was used to investigate the surface properties of the sample.

2.3. Synthesis. Hydroxymethylferrocene was synthesized according to the literature [40]. Iodomethane (21.9 g, $0.155 \mathrm{~mol})$ in methanol $(25 \mathrm{~mL})$ was treated dropwise with dimethylamino (dimethylferoccene) $(25 \mathrm{~g}, 0.103 \mathrm{~mol})$ in 


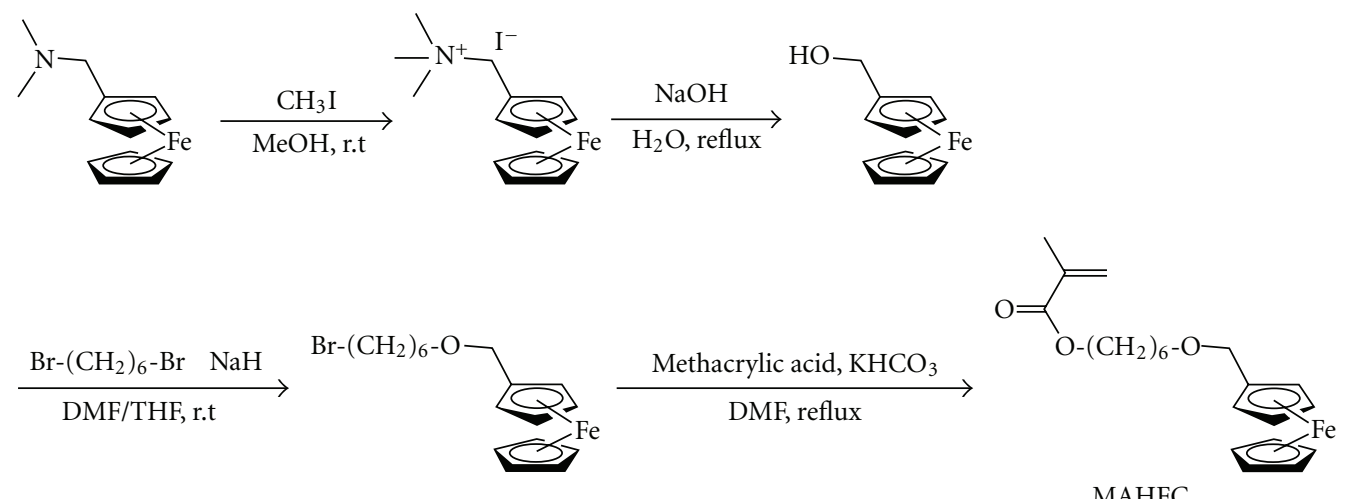

FIGURE 1: Synthesis of MAHFC monomer.

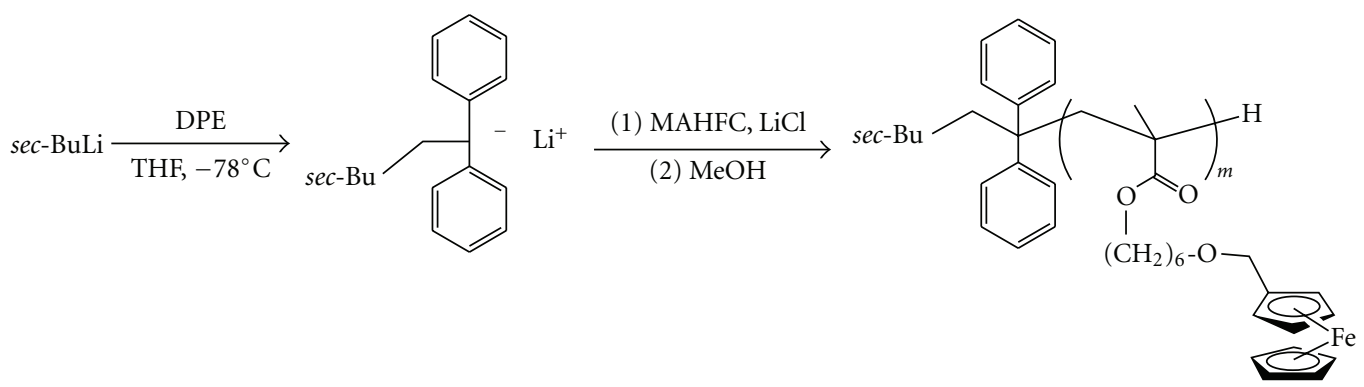

FIGURE 2: Synthesis of PMAHFC homopolymer by living anion polymerization.

methanol $(20 \mathrm{~mL})$ and stirred for $4 \mathrm{~h}$ at room temperature. Diethyl ether was then added to the mixture and the resulting precipitate was filtered and dried in vacuo at $30^{\circ} \mathrm{C}$ for $3 \mathrm{~h}$ (37.2 g, 94\%).

N,N,N-trimethylaminomethyl-ferrocene iodine $(20.0 \mathrm{~g}$, $0.052 \mathrm{~mol}$ ) was added to a $2 \mathrm{~N}$ sodium hydroxide solution $(200 \mathrm{~mL})$ and the mixture was refluxed overnight. The reaction mixture was then diluted with diethyl ether and washed with brine. The organic layer was dried over magnesium sulfate $\left(\mathrm{MgSO}_{4}\right)$, filtered, and evaporated. The yellow residue was purified by recrystallization from $n$-hexane. The yellow needles were dried in vacuo at $30^{\circ} \mathrm{C}$ for 4 hours $(8.1 \mathrm{~g}, 72 \%)$; m.p.; $77-78^{\circ} \mathrm{C} ;{ }^{1} \mathrm{H} \mathrm{NMR}\left(\mathrm{CDCl}_{3}\right.$, r.t): $\delta 1.53(1 \mathrm{H},-\mathrm{OH}), 4.24$ $(7 \mathrm{H}, \mathrm{H}), 4.26(2 \mathrm{H}, \mathrm{H}), 4.32\left(2 \mathrm{H},-\mathrm{CH}_{2}\right)$.

2.4. 1-Bromo-6-ferrocenylmethoxy-hexane. A round-bottomed flask was charged with sodium hydride $(0.79 \mathrm{~g}$, $0.033 \mathrm{~mol})$ and THF $(10 \mathrm{~mL})$ in a nitrogen atmosphere. A solution of 1,6-dibromohexane $(8.08 \mathrm{~g}, 0.033 \mathrm{mmol})$ and hydroxymethylferrocene $(7.25 \mathrm{~g}, 0.033 \mathrm{mmol})$ in $N, N$ dimethylformamide (DMF)/THF $(20 \mathrm{~mL}$ each) was added to the mixture and the mixture was kept at $0^{\circ} \mathrm{C}$ using an ice bath. After $24 \mathrm{~h}$, the reaction mixture was diluted with $n$-hexane and washed with brine several times to remove the DMF and excess sodium hydride. The organic layer was dried over $\mathrm{MgSO}_{4}$, filtered, and evaporated. The dark red residue was purified by column chromatography on silica using $n$-hexane. The solvent was removed and the dark red liquid was dried in vacuo at room temperature for $3 \mathrm{~h}(7.20 \mathrm{~g}$,
$18.9 \mathrm{mmol}, 57 \%)$. IR (KBr): 3094, 2954, 2867, 1100, 1000, $654 \mathrm{~cm}^{-1}$; ${ }^{1} \mathrm{H}$ NMR $\left(\mathrm{CDCl}_{3}, \mathrm{rt}\right): \delta 4.89$ and $4.26-4.09(9 \mathrm{H}$, cyclopentadienyl), $3.40\left(\mathrm{~m}, 4 \mathrm{H},-\mathrm{CH}_{2}-\mathrm{O}-\mathrm{CH}_{2}\right.$-ferrocene), $1.84\left(\mathrm{~m}, 2 \mathrm{H}, \mathrm{Br}-\mathrm{CH}_{2}-\mathrm{CH}_{2}-\right), 1.58$ ( $\mathrm{m}, 4 \mathrm{H}$, alkyl chain), 1.38 (m, $4 \mathrm{H}$, alkyl chain); ${ }^{13} \mathrm{C} \mathrm{NMR}\left(\mathrm{CDCl}_{3}, \mathrm{rt}\right): \delta 83.6,77.2$, 69.7, 69.4, 69.0, 68.3, 33.9, 32.7, 29.5, 27.9, $25.3 \mathrm{ppm}$.

2.5. Synthesis of MAHFC. A round-bottomed flask was charged with 1-bromo-6-ferrocenylmethoxy-hexane $(1.50 \mathrm{~g}$, $3.95 \mathrm{mmol})$ in DMF $(24 \mathrm{~mL})$. The methacrylic acid salt was prepared by mixing methacrylic acid $(0.68 \mathrm{~g}, 7.90 \mathrm{mmol})$ and sodium hydrogen carbonate $(0.79 \mathrm{~g}, 7.90 \mathrm{mmol})$ and was added to the flask along with a small amount of hydroquinone as an inhibitor. The resulting solution was heated to $100^{\circ} \mathrm{C}$ over the course of $6 \mathrm{~h}$ in a nitrogen atmosphere. The reaction mixture was then diluted with $n$ hexane and washed with brine. The organic layer was dried over $\mathrm{MgSO}_{4}$, filtered, and evaporated. The dark red residue was purified by column chromatography on silica using $n$ hexane. The solvent was removed and a dark red liquid was obtained (1.31 g, $3.42 \mathrm{mmol}, 86 \%)$. IR (KBr): 3093, 2951, 2869, 1730, 1640, 1100, $1000 \mathrm{~cm}^{-1} .{ }^{1} \mathrm{H}$ NMR $\left(\mathrm{CDCl}_{3}, \mathrm{rt}\right): \delta$ $6.10\left(\mathrm{~s}, 1 \mathrm{H}, \mathrm{C}=\mathrm{CH}_{2}\right), 5.56\left(\mathrm{~s}, 1 \mathrm{H}, \mathrm{C}=\mathrm{CH}_{2}\right), 4.26-4.13(\mathrm{br}$, $11 \mathrm{H}$, cyclopentadienyl and $\left.-\mathrm{COO}-\mathrm{CH}_{2}-\right), 3.39$ (br, $2 \mathrm{H},-$ $\mathrm{O}-\mathrm{CH}_{2}$-ferrocene), $1.95\left(\mathrm{~s}, 3 \mathrm{H},-\mathrm{CH}_{3}\right), 1.54(\mathrm{~m}, 4 \mathrm{H}$, alkyl chain), 1.34 (s, 4H, alkyl chain); ${ }^{13} \mathrm{C} \mathrm{NMR}\left(\mathrm{CDCl}_{3}, \mathrm{rt}\right): \delta$ $1637.3,136.3,127.2,125.0,83.5,79.7,77.4,69.6,69.2,68.9$, $68.2,64.5,29.4,28.4,25.7,18.2 \mathrm{ppm}$. 


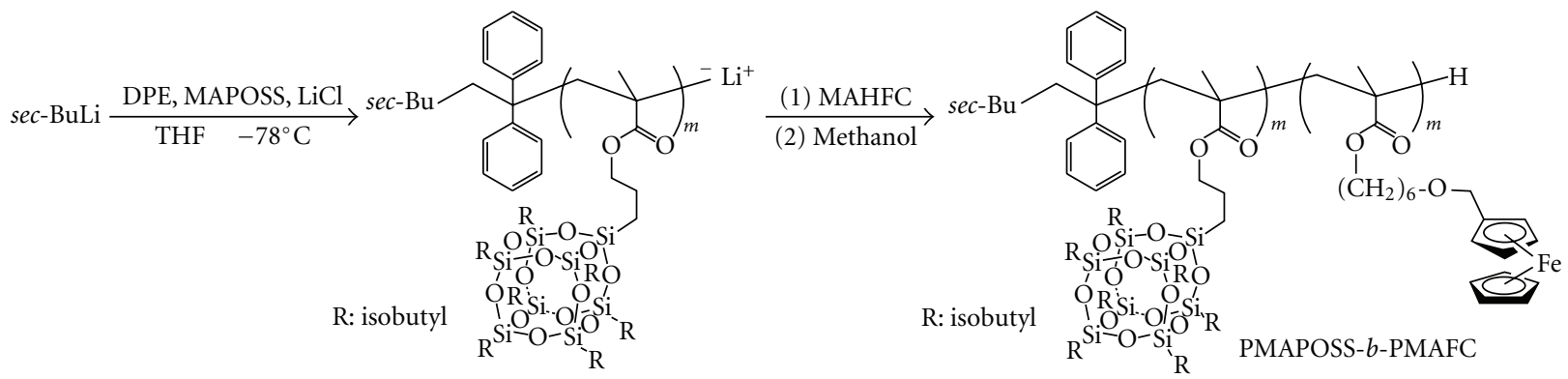

FIgURE 3: Synthesis of PMAPOSS- $b$-PMAHFC by living anion polymerization.

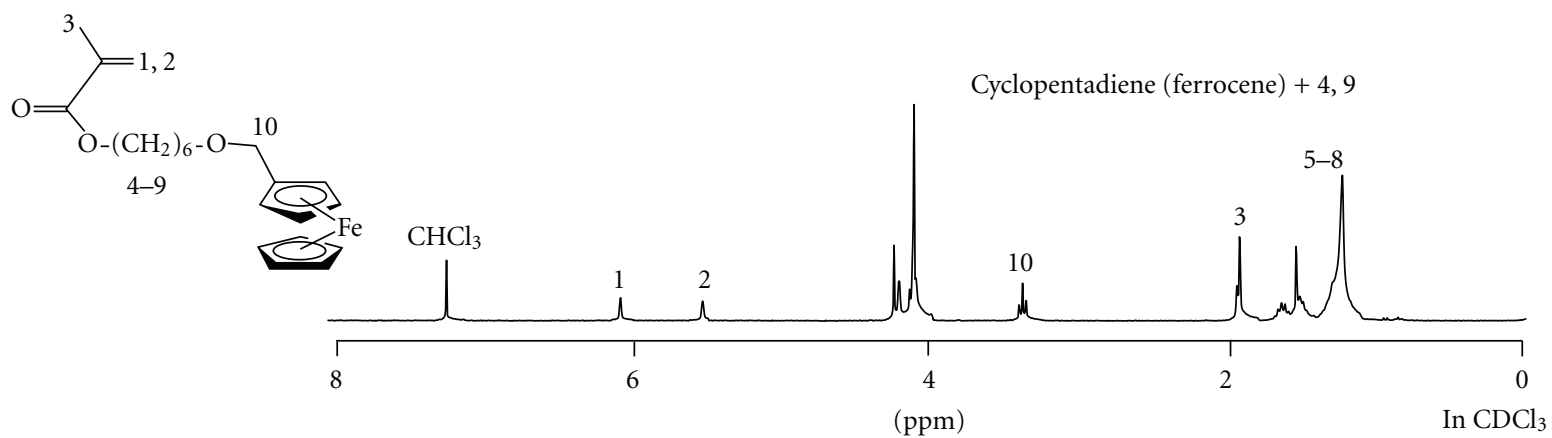

(a)

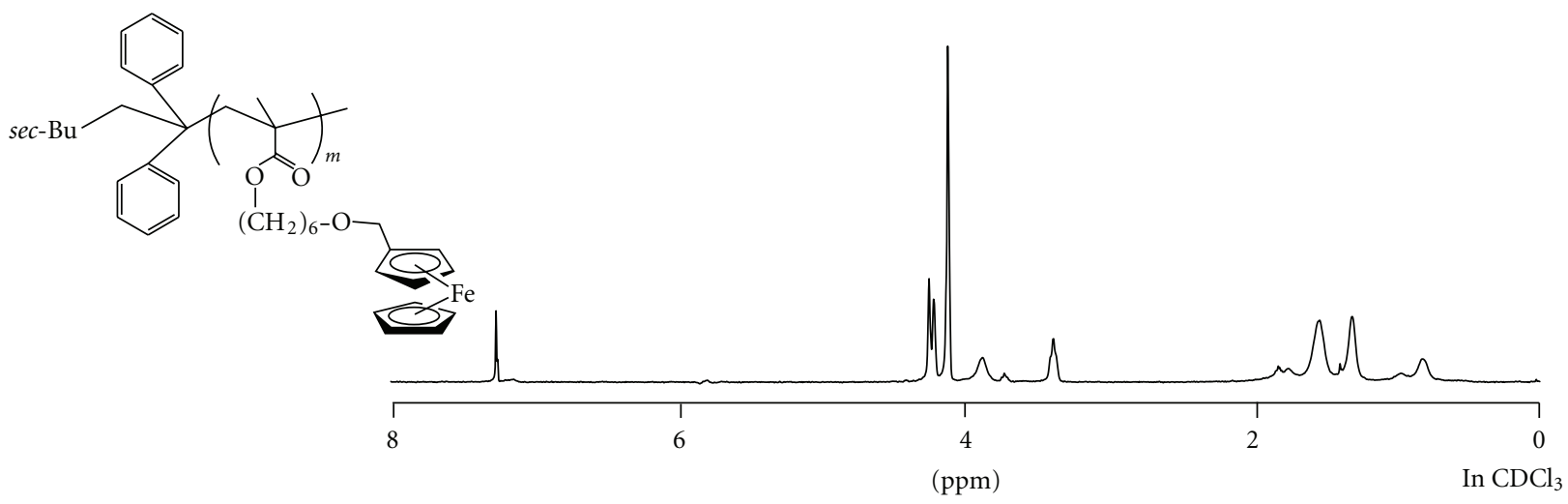

(b)

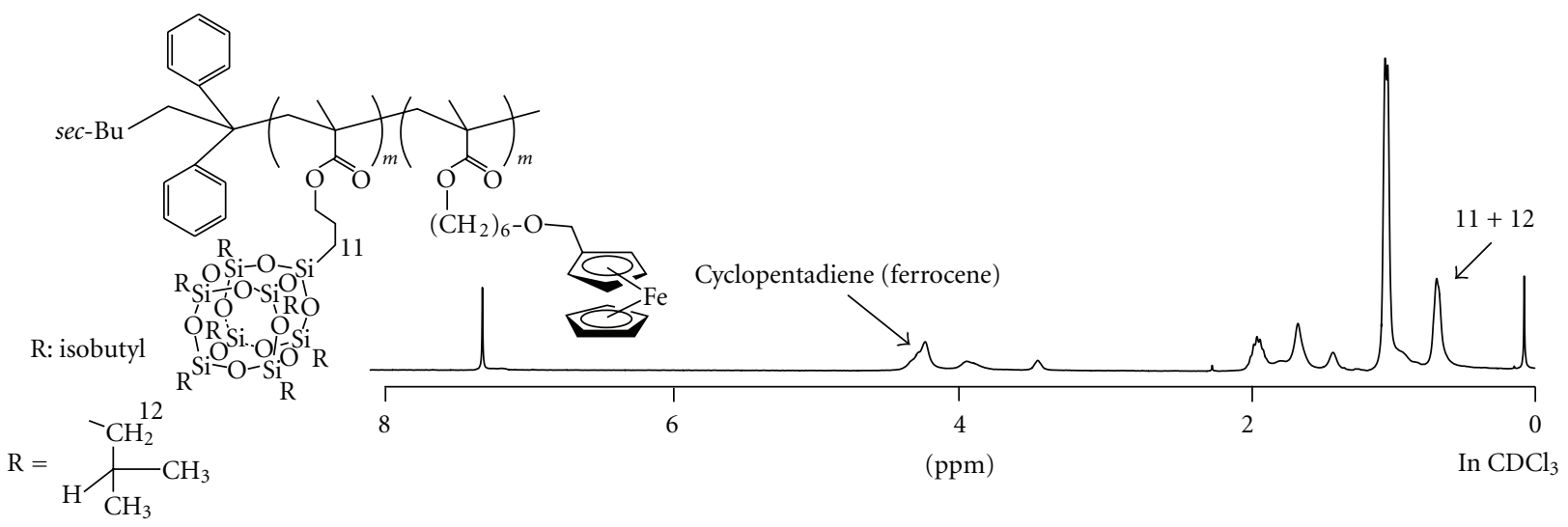

(c)

Figure 4: ${ }^{1} \mathrm{H}$ NMR spectra of (a) MAHFC, (b) PMAHFC, and (c) PMAPOSS- $b$-PMAHFC. 


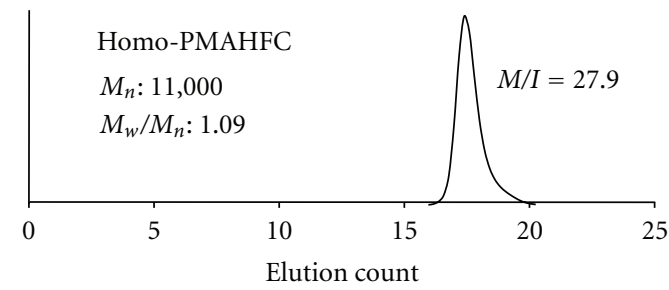

(a)

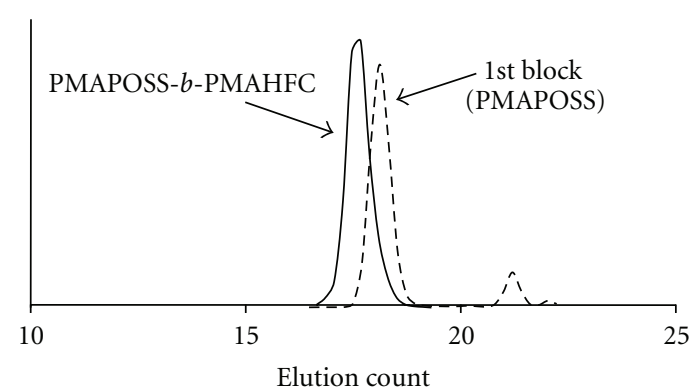

(b)

Figure 5: SEC curves of (a) PMAHFC homopolymer and (b) PMAPOSS-b-PMAHFC (solid line) and PMAPOSS (dashed line).

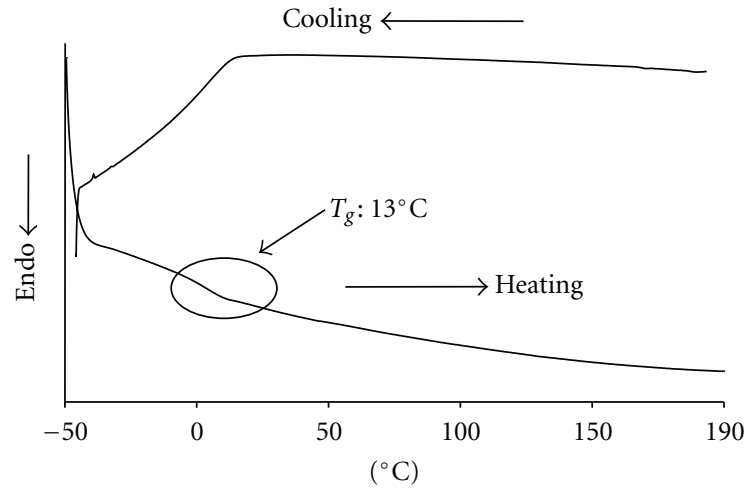

Figure 6: DSC trace of PMAPOSS- $b$-PMAHFC 2 (from $-50^{\circ} \mathrm{C}$ to $\left.190^{\circ} \mathrm{C}\right)$.

2.6. Synthesis of PMAHFC Homopolymer by Living Anionic Polymerization. THF $(40 \mathrm{~mL})$ was transferred to a glass reactor equipped with stir bar containing dry $\mathrm{LiCl}$ (15 mg, $0.36 \mathrm{mmol}$ ) and cooled to $-78^{\circ} \mathrm{C}$. After $5 \mathrm{~min}$, sec-BuLi was added until the color changed to slightly yellow. The reactor was removed from the cooling bath and allowed to reach room temperature, upon which the solution became colorless. The reactor was cooled back to $-78^{\circ} \mathrm{C}$, and $1.07 \mathrm{M}$ sec-BuLi solution in hexane/cyclohexane $(0.025 \mathrm{~mL}$, $0.027 \mathrm{mmol}$ ) was added. After $5 \mathrm{~min}$, DPE $(0.025 \mathrm{~mL}$, $0.14 \mathrm{mmol}$ ) was added to the reactor, resulting in the formation of a deep red color. After $30 \mathrm{~min}$, MAHFC that had been dried under reduced pressure for several hours $(0.30 \mathrm{~g}$, $0.78 \mathrm{mmol})$ was dissolved in THF $(4.0 \mathrm{~mL})$ and transferred from the monomer reservoir to the polymerization flask via cannula with vigorous stirring. The solution changed from deep red to orange. After $8 \mathrm{~h}$ at $-78^{\circ} \mathrm{C}$, excess of methanol was added to the reactor to obtain the proton-terminated polymer. This was then precipitated into a large excess amount of methanol, filtered, and dried in vacuo at $80^{\circ} \mathrm{C}$ for $6 \mathrm{~h}$, yielding $0.28 \mathrm{~g}$ of polymer. IR $(\mathrm{KBr}): 3093,2951,2869$, $1730,1640,1100,1000 \mathrm{~cm}^{-1} .{ }^{1} \mathrm{H}$ NMR $\left(\mathrm{CDCl}_{3}, \mathrm{rt}\right): \delta 4.26-$ 4.13 (br, cyclopentadienyl), 3.89 (br, $-\mathrm{O}-\mathrm{CH}_{2}-$ ferrocene), 3.40 (br, $-\mathrm{O}-\mathrm{CH}_{2}-\mathrm{CH}_{2}$,), 1.85-1.78 (m, main chain), 1.561.34 (br, alkyl side chain), $0.85\left(\mathrm{~m}, \alpha \mathrm{CH}_{3}\right) ;{ }^{13} \mathrm{C} \mathrm{NMR}$ $\left(\mathrm{CDCl}_{3}, \mathrm{rt}\right): \delta 177.7,83.7,69.8,69.4,69.0,68.44,68.40,54.1$, 51.8, 44.8, 44.5, 29.6, 28.1, 25.8 ppm.
2.7. Synthesis of PMAPOSS- $b$-PMAHFC by Living Anionic Polymerization. THF $(40 \mathrm{~mL})$ was transferred to a glass reactor equipped with a stirrer bar containing dry $\mathrm{LiCl}$ $(15 \mathrm{mg}, 0.36 \mathrm{mmol})$, and then cooled to $-78^{\circ} \mathrm{C}$. After $5 \mathrm{~min}$, sec-BuLi was added until the color changed to slightly yellow. The reactor was removed from the cooling bath and allowed to reach room temperature upon which the solution became colorless. The reactor was cooled back to $-78^{\circ} \mathrm{C}$ and $1.07 \mathrm{M} \mathrm{sec}$-BuLi solution in hexane/cyclohexane $(0.025 \mathrm{~mL}$, $0.027 \mathrm{mmol})$ was added. After 5 additional minutes, DPE $(0.025 \mathrm{~mL}, 0.14 \mathrm{mmol})$ was added to the reactor resulting in the formation of a deep red color. After $30 \mathrm{~min}$, MAPOSS $(0.5 \mathrm{~g}, 0.5 \mathrm{mmol})$ was dissolved in THF $(4.0 \mathrm{~mL})$ and transferred from the monomer reservoir to the polymerization flask via cannula with vigorous stirring. The deep red color changed to colorless. In a second sample, MAHFC ( $0.4 \mathrm{~g}$, $0.78 \mathrm{mmol})$ was dissolved in THF $(4.0 \mathrm{~mL})$. After $8 \mathrm{~h}$, the MAHFC solution was transferred to the polymerization flask via cannula. After additional $8 \mathrm{~h}$ at $-78^{\circ} \mathrm{C}$, excess methanol was added to the reactor yielding the proton terminated diblock copolymer. This was then precipitated into methanol, filtered, and dried in vacuo at $60^{\circ} \mathrm{C}$ for 8 h. IR (KBr): 3094, 2953, 2868, 1730, 1643, 1260, 1100, $1000 \mathrm{~cm}^{-1} \cdot{ }^{1} \mathrm{H}$ NMR $\left(\mathrm{CDCl}_{3}, \mathrm{rt}\right): \delta 4.25-4.10$ (br, ferrocene, PMAHFC), 3.86 (br, -O- $\mathrm{CH}_{2}$-ferrocene), 3.37 (br, -O$\mathrm{CH}_{2}-\mathrm{CH}_{2}$, PMAHFC), $1.84-1.78$ (br, main chain $-\mathrm{CH}_{2}$, CH, PMAPOSS, PMAHFC), 1.53-1.31 (br, alkyl side chain, PMAHFC), 0.98 (br, isobutyl $-\mathrm{C}\left(\mathrm{CH}_{3}\right)_{2}$, PMAPOSS), 0.81 $\left(\mathrm{m}, \alpha \mathrm{CH}_{3}, \mathrm{PMAPOSS}\right.$ and PMAHFC), 0.55 (br, $-\mathrm{SiCH}_{2}$, PMAPOSS $) ;{ }^{13} \mathrm{C} \mathrm{NMR}\left(\mathrm{CDCl}_{3}, \mathrm{rt}\right): \delta 177.7,176.9,83.7,69.8$, $69.4,69.0,68.44,68.40,67.2,54.1,51.8,45.2,44.8,44.5$, 29.6, 28.1, 26.0, 25.8, 25.7, 25.5, 24.0, 23.8, 22.5, 22.4, 21.8, 8.4 ppm.; ${ }^{29} \mathrm{Si} \mathrm{NMR}\left(\mathrm{CDCl}_{3}, \mathrm{rt}\right): \delta-67.6,-67.9 \mathrm{ppm}$.

\section{Results and Discussion}

3.1. Synthesis and Polymerization of Ferrocene-Containing Monomer. The procedure for synthesizing MAHFC, with a hexyl chain between the ferrocene moiety and methacrylate group, is illustrated in Figure 1. The role of the hexyl chain is to prevent strong interactions between ferrocene groups. The hydroxymethylferrocene was first prepared according 

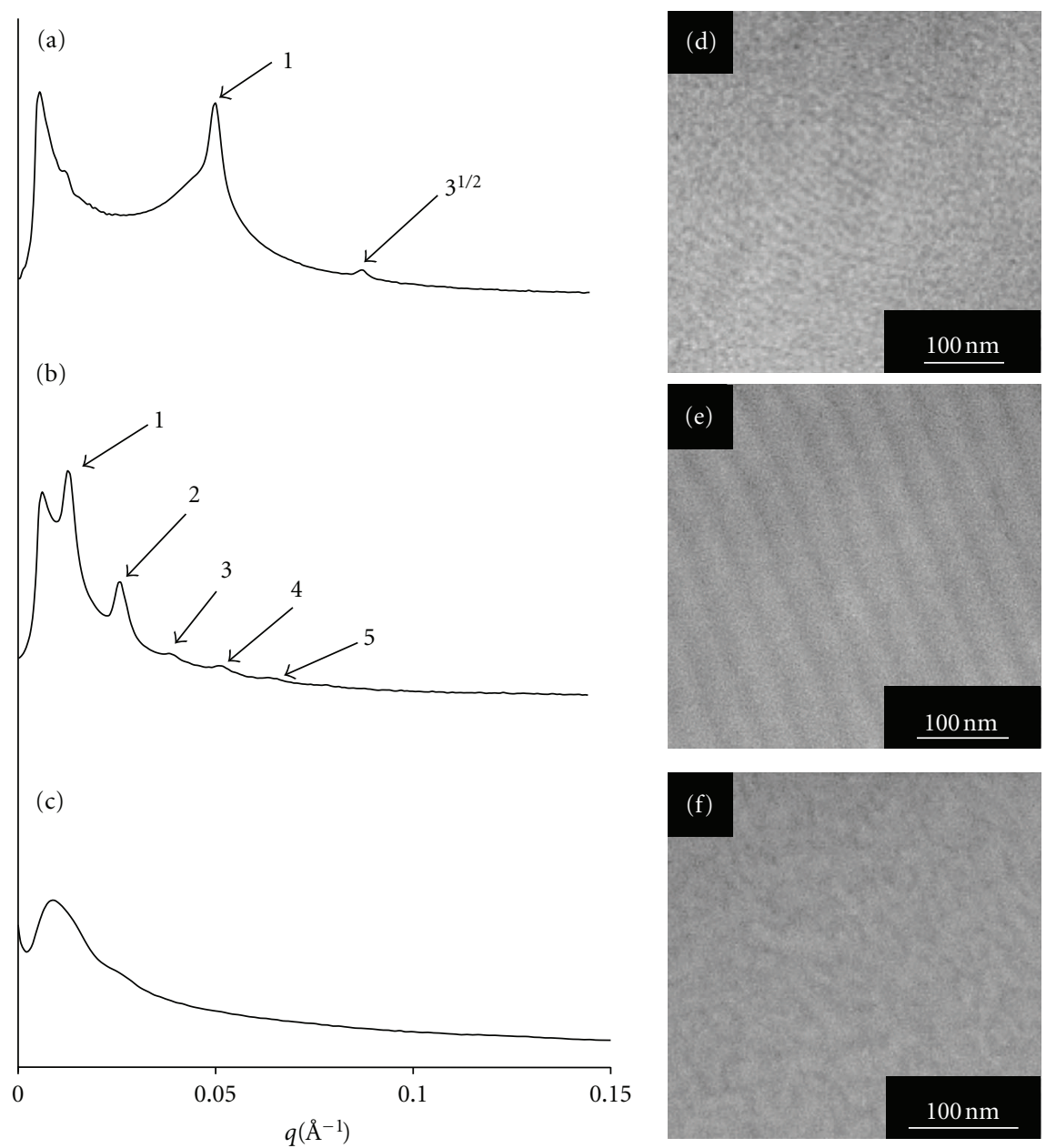

Figure 7: SAXS profiles (a, b, c) and TEM images (d, e, f) of PMAPOSS- $b$-PMAHFC 1-3; (a) and (d) PMAPOSS- $b$-PMAHFC 1; (b) and (e) PMAPOSS- $b$-PMAHFC 2; (c) and (f) PMAPOSS- $b$-PMAHFC 3. Brighter region corresponds to PMAPOSS domain and darker region corresponds to PMAHFC domain.

to the literature. It then underwent etherification with 1,6dibromohexane to obtain 1-bromo-6-ferrocenylmethoxyhexane. Finally, the MAHFC monomer was yielded as a dark red liquid after esterification of methacrylic acid. The monomer was characterized by ${ }^{1} \mathrm{H}$ and ${ }^{13} \mathrm{C}$ NMR and IR spectroscopy. Figure 4(a) shows ${ }^{1} \mathrm{H}$ NMR spectrum of MAHFC, which exhibits the resonance signals of the double bond (peaks a and b) and the ferrocene moiety. The characteristic peaks of the two carbons of the double bond appear at 136.3 and $125.0 \mathrm{ppm}$ in the ${ }^{13} \mathrm{C}$ NMR spectrum. There is also a series of peaks between 68.4 and $69.8 \mathrm{ppm}$ from the ten carbons of the ferrocene group. These observations indicate that the desired MAHFC was successfully obtained.

Living anionic polymerization of MAHFC was employed in order to control both the molecular weights and molecular weight distributions of the resulting block copolymers. The polymerization was carried out using 1,1-diphenyl3-methyl-pentyllithium as the initiator, prepared by the reaction of sec-BuLi and DPE in the presence of a 5-fold excess of $\mathrm{LiCl}$ in $\mathrm{THF}$ at $-78^{\circ} \mathrm{C}$ for $8 \mathrm{~h}$ to ensure complete conversion was achieved (Figure 2). Finally, the active chains were terminated at $-78^{\circ} \mathrm{C}$ using degassed methanol, and the products were precipitated in a large volume of methanol at room temperature. After precipitation, the methanol solution remained colorless, thereby verifying the absence of unreacted monomers and oligomers. The purification was carried out by reprecipitation into a large volume of methanol, twice, and PMAHFC was obtained as a yellowishorange powder. All the signals and peaks of PMAHFC were accurately assigned in the ${ }^{1} \mathrm{H}$ and ${ }^{13} \mathrm{C}$ NMR and IR spectra. SEC was performed on PMAHFC to determine its number average molecular weight $\left(M_{n}\right)$ and polydispersity index (PDI). The chromatogram demonstrates a sharp unimodal peak (Figure 5(a)). The $M_{n}$ and PDI were found to be $11000 \mathrm{~g} \mathrm{~mol}^{-1}$ and 1.09 , respectively, indicating that the living anionic polymerization of MAHFC successfully afforded the polymer with a controlled $M_{n}$ and narrow PDI.

Based on the success of the homopolymerization of MAHFC, the synthesis of the block copolymer PMAPOSS$b$-PMAHFC was carried out (Figure 3). The MAHFC was added as a second monomer to the living PMAPOSS reaction 


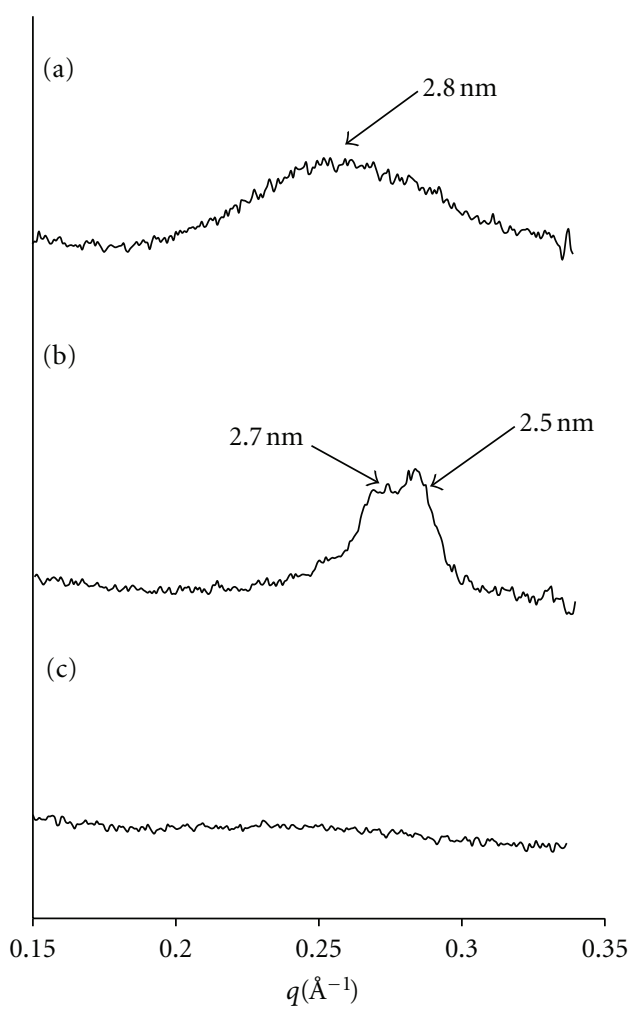

FIGURE 8: WAXS profiles of (a) PMAPOSS- $b$-PMAHFC 1, (b) PMAPOSS- $b$-PMAHFC 2 , and (c) PMAPOSS- $b$-PMAHFC 3.

mixture and the polymerization proceeded homogeneously, with no precipitation observed until the reaction was terminated. In this study, three PMAPOSS- $b$-PMAHFCs, $\mathbf{1}$, 2, and 3, with different molecular weights and compositions were prepared (Table 1). The chemical compositions of the block copolymers were characterized by ${ }^{1} \mathrm{H},{ }^{13} \mathrm{C}$, and ${ }^{29} \mathrm{Si}$ NMR and IR spectroscopies, and the $M_{n}$ values were measured using SEC. Figure 4 shows the ${ }^{1} \mathrm{H}$ NMR spectra of the MAHFC monomer, PMAHFC homopolymer, and PMAPOSS- $b$-PMAHFC. The ${ }^{1} \mathrm{H}$ NMR spectrum of PMAPOSS- $b$-PMAHFCs clearly shows that the incorporation of each block was successful, which is indicated by the appearance of methylene $\left(-\mathrm{OSiCH}_{2}\right)$ protons corresponding to PMAPOSS at $0.59 \mathrm{ppm}$ and cyclopentadienyl protons corresponding to ferrocene groups in PMAHFC at 4.1$4.3 \mathrm{ppm}$. The SEC chromatograms of the polymers show that the $M_{n}$ increased in a controlled manner, which is reflected by the shift to the higher molecular weight region (Figure 5(b)). The SEC analysis showed that the PDI for all polymers was below 1.08. The compositions of PMAPOSS$b$-PMAHFCs were ascertained by using the ${ }^{1} \mathrm{H}$ NMR spectra integration ratios of methylene protons for PMAPOSS and ferrocene protons from PMAHFC, along with the $M_{n}$ values. The thermal properties of PMAHFC and the PMAPOSS$b$-PMAHFCs were investigated using TGA and DSC. To eliminate the effect of thermal histories of the samples, the samples were heated to $200^{\circ} \mathrm{C}$ and held for $10 \mathrm{~min}$ at this temperature before cooling to $-50^{\circ} \mathrm{C}$ at a rate of $10^{\circ} \mathrm{C} \mathrm{min}{ }^{-1}$. The DSC trace of PMAPOSS- $b$-PMAHFC
2 on the second heating showed baseline shifts at $13^{\circ} \mathrm{C}$ corresponding to the $T_{g}$ of the PMAHFC block segment (Figure 6). The $T_{g}$ of PMAHFC is significantly lower than that of poly(ferrocenyl methacrylate) $\left(185^{\circ} \mathrm{C}\right)$. The alkyl chain in the ferrocene-tethered side chains might decrease the interactions between the ferrocene moieties increasing the conformational flexibility of the side chains.

3.2. Bulk Morphological Characterization. The morphologies of the PMAPOSS- $b$-PMAHFCs in their bulk state were studied using WAXS, SAXS, and TEM. The samples were prepared by slow evaporation from chloroform at room temperature. For TEM measurement, all samples were imaged without staining as the contrast between the ferrocenecontaining block (dark regions) and the POSS-containing block (bright regions) was sufficient for achieving highquality images.

Figure 7 shows SAXS and TEM results for PMAPOSS$b$-PMAHFCs 1-3. The SAXS profile of the PMAPOSS- $b$ PMAHFC 1 exhibits first-order and second-order diffraction peaks, with ratios of 1 and $3^{1 / 2}$, respectively. The TEM image of PMAPOSS- $b$-PMAHFC 1 shows PMAHFC cylindrical nanostructures, which is strongly supported by the SAXS results. On increasing the PMAHFC wt $\%$ to 0.33 , clear microphase-separated nanostructures were observed. The scattering profiles show up to five peaks with a characteristic ratio of $1: 2: 3: 4: 5$, indicating a lamellar morphology. The lamellar $d$-spacing was found to be $49 \mathrm{~nm}$, which is in good agreement with values obtained from the TEM image. Although the molecular weight and the composition of PMAPOSS- $b$-PMAHFC 3 are theoretically sufficient to enable microphase separation, the TEM image shows no well-defined microphase-separated nanostructures. In order to investigate this sample further, WAXS measurements were performed. The WAXS patterns of PMAPOSS- $b$ PMAHFC 1 and 2 (Figure 8) show some peaks in the high $q$ region corresponding to a $d$ spacing of $2.5-2.7 \mathrm{~nm}$, but no diffraction peaks are evident for PMAPOSS- $b$-PMAHFC 3. As previously reported, these diffraction peaks correspond to the distance between the PMAPOSS chains in the selfassembled structures [30]. These results indicate that the microphase separation and the aggregation of PMAPOSS chains can only occur when the content of PMAHFC in the PMAPOSS- $b$-PMAHFC copolymer is low.

\subsection{Thin Film Nanostructures and Oxygen Plasma Treatment.} In order to investigate the nanostructures of the thin films, solutions of the PMAPOSS- $b$-PMAHFCs in THF $(1.0 \%-2.0 \%, \mathrm{w} / \mathrm{w})$ were spin coated onto silicon wafers. Prior to coating, the substrates were cleaned with piranha solution $\left(30 \% \mathrm{H}_{2} \mathrm{O}_{2} / 70 \% \mathrm{H}_{2} \mathrm{SO}_{4}, \mathrm{v} / \mathrm{v}\right)$ at $110^{\circ} \mathrm{C}$ for $2 \mathrm{~h}$, rinsed thoroughly with distilled water, and dried under a stream of nitrogen. The morphology of the thin films of the PMAPOSS- $b$-PMAHFCs was characterized by SEM, and the thickness of the films was estimated using ellipsometry. The as-cast thin film prepared from a THF solution of PMAPOSS- $b$-PMAHFC 2 had a thickness of $47 \mathrm{~nm}$ and did not show any ordered nanostructures caused by microphase 

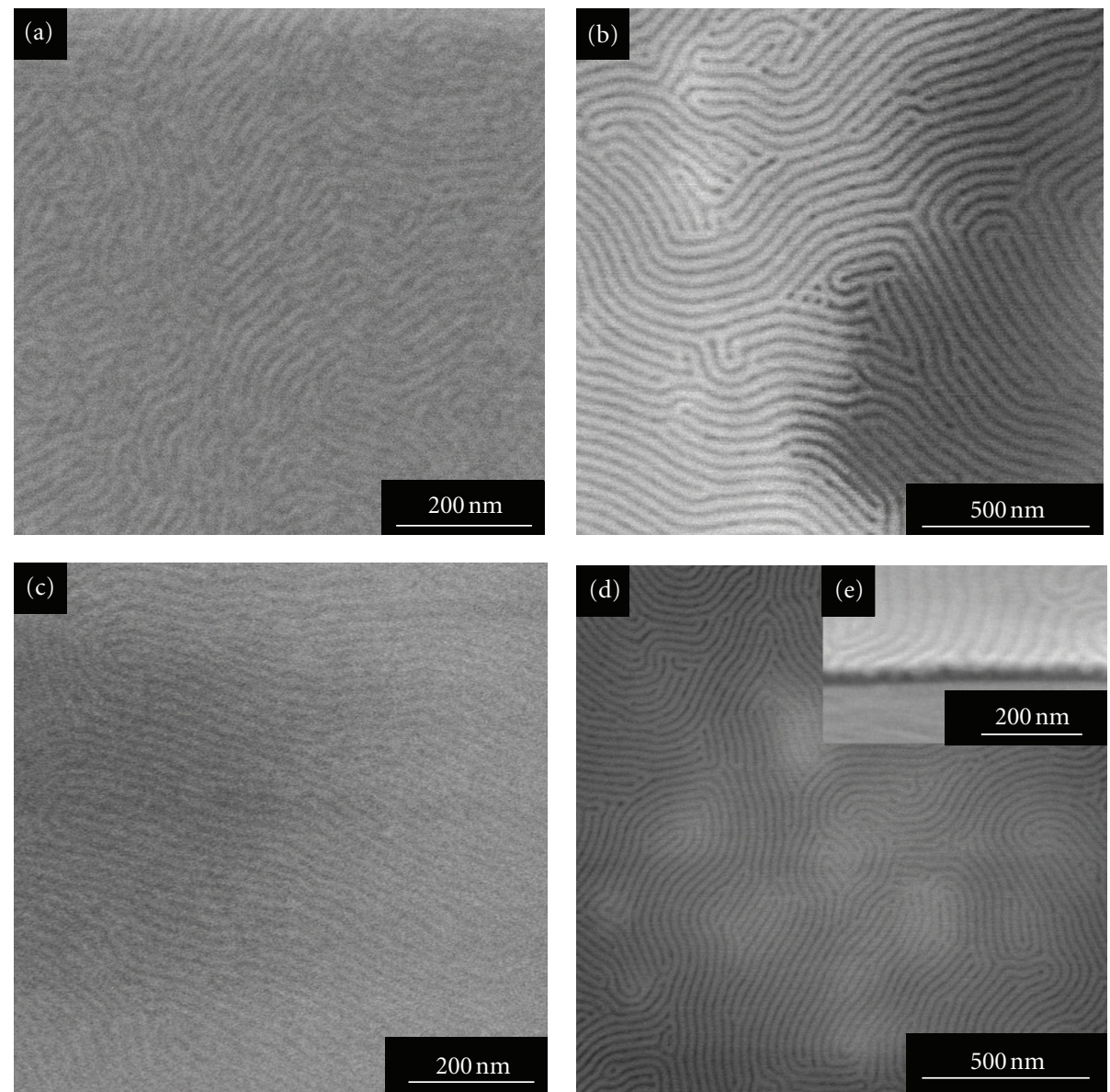

FIgure 9: SEM images of thin films (a) PMAPOSS- $b$-PMAHFC 1, (b) PMAPOSS- $b$-PMAHFC 2, (c) oxygen plasma treated PMAPOSS- $b$ PMAHFC 1, and (d) oxygen plasma treated PMAPOSS- $b$-PMAHFC 2, the inset (e) is the cross-sectional SEM image of (d).

TABLE 1: Characteristics of block copolymers based on SEC and ${ }^{1} \mathrm{H}$ NMR analyses.

\begin{tabular}{|c|c|c|c|c|c|}
\hline PMAPOSS- $b$-PMAHFC & $M_{n}{ }^{\mathrm{a}}$ & $M_{w}{ }^{\mathrm{a}}$ & $\mathrm{PDI}^{\mathrm{a}}$ & wt $\%$ PMAPOSS $^{\mathrm{b}}$ & wt $\%$ PMAHFC \\
\hline 1 & 16,300 & 17,300 & 1.06 & 75 & 25 \\
\hline 2 & 49,000 & 52,600 & 1.07 & 67 & 33 \\
\hline 3 & 56,100 & 60,400 & 1.08 & 42 & 58 \\
\hline
\end{tabular}

${ }^{a}$ Measured by SEC, relative to PS linear standard. ${ }^{\mathrm{b}}$ The numbers refer to the final composition determined by SEC calibrated against PS linear standard and integrations from ${ }^{1} \mathrm{H}$ NMR spectrum.

separation. Solvent and thermal annealing were carried out in order to initiate reassembly of the polymer chains to induce microphase separation. However, the thermal annealing did not affect the results with a wide range of temperatures and annealing times tested. Solvent annealing was therefore subsequently investigated. Solvent annealing of PMAPOSS- $b$-PMAHFC was performed using carbon disulfide $\left(\mathrm{CS}_{2}\right)$ because it was found that it could swell both PMAHFC and PMAPOSS. Thin films of PMAPOSS- $b$ PMAHFC 1 and 2 were annealed in saturated $\mathrm{CS}_{2}$ vapor at room temperature for $5 \mathrm{~min}$ and $10 \mathrm{~min}$, respectively. SEM images of the resulting films showed line nanostructures on the surface with $d$ spacings of $19 \mathrm{~nm}$ (Figure 9(a)) and $46 \mathrm{~nm}$ (Figure 9(b)), respectively. Under these specific solvent annealing conditions, no dewetting was seen to occur. In Figure 9, the brighter region corresponds to the PMAPOSS blocks. Because the PMAPOSS blocks tend to discharge more secondary electrons than the PMAHFC blocks.

Finally, in order to create the arrays of iron oxides, oxygen plasma treatment was carried out for $30 \mathrm{~s}$ on the series of PMAPOSS- $b$-PMAHFC thin films. The SEM images of the exposed films clearly show the remaining microphaseseparated nanostructures. As shown in Figure 9(e), the cross-sectional SEM image of the PMAPOSS- $b$-PMAHFC 2 thin film treated with oxygen plasma indicates that perpendicular lamella formed through the entire $47 \mathrm{~nm}$ thick film. The XPS spectrum of PMAPOSS- $b$-PMAHFC 1 shown in Figure 10 exhibits a peak corresponding to $\mathrm{Fe}_{2 \mathrm{p} 3 / 2}$ at $711 \mathrm{eV}$ (Figure 10). This indicates that iron oxides 


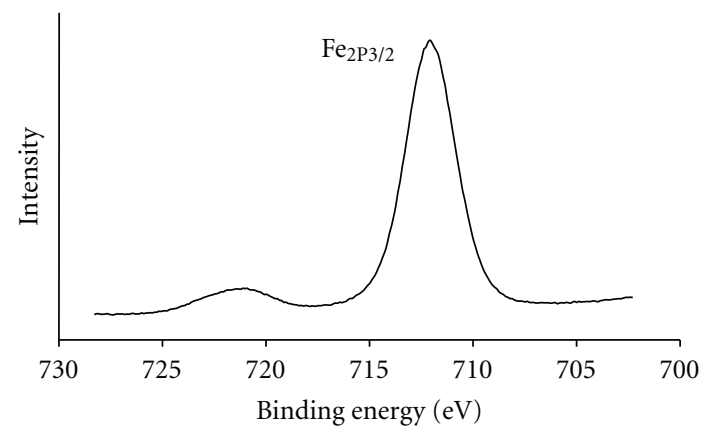

FIGURE 10: XPS spectrum in the range $730-700 \mathrm{eV}$ for oxygen plasma-treated PMAPOSS- $b$-PMAHFC 1 thin film.

were generated by oxidation of the ferrocene moiety on the PMAPOSS- $b$-PMAHFCs at the thin film surface. These characterizations show that a well-defined line array of iron oxides was obtained, without any collapse, by simple oxygen plasma treatment of PMAPOSS- $b$-PMAHFC thin films. The catalytic ability for CNT growth is still under investigation, and will be described in a subsequent report.

\section{Conclusion}

In conclusion, a new series of POSS-containing block copolymers with a ferrocene-containing side-chain polymer of PMAHFC was prepared using living anionic polymerization. The use of this method enabled control of the molecular weights and the achievement of a narrow PDI below 1.08. PMAHFC demonstrated a $T_{g}$ at $13^{\circ} \mathrm{C}$, which is much lower than that of conventional ferrocene-containing side-chain polymers such as PFMMA. Microphase separation occurred only when the content of PMAHFC in the PMAPOSS- $b$ PMAHFC copolymer was below $33 \mathrm{wt} \%$. The line nanostructures in the thin films were formed using solvent annealing, and subsequent oxygen plasma treatment provided line arrays of iron oxides based on the microphase-separated nanostructures. This array is expected to be a promising catalytic material for the creation of CNT thin films.

\section{Acknowledgments}

The authors thank Ryohei Kikuchi, National University Corporation Tokyo Institute of Technology Center for Ascended Materials Analysis, for the TEM. The authors acknowledge NSRRC, Taiwan, for facilitating the SAXS and WAXS experiments performed as part of this work and Dr. U-Ser Jeng of NSRRC for assistance with these experiments. R. Goseki and T. Hayakawa gratefully thank Professor Sang-Ouk Kim (Korea Advanced Institute of Science and Technology) for his useful discussions.

\section{References}

[1] M. Lazzari and M. A. López-Quintela, "Block copolymers as a tool for nanomaterial fabrication," Advanced Materials, vol. 15, no. 19, pp. 1583-1594, 2003.
[2] C. Park, J. Yoon, and E. L. Thomas, "Enabling nanotechnology with self assembled block copolymer patterns," Polymer, vol. 44, no. 22, pp. 6725-6760, 2003.

[3] J. Y. Cheng, C. A. Ross, H. I. Smith, and E. L. Thomas, "Templated self-assembly of block copolymers: top-down helps bottom-up," Advanced Materials, vol. 18, no. 19, pp. 2505-2521, 2006.

[4] M. Park, C. Harison, P. M. Chaikin, R. A. Register, and D. H. Adamson, "Block copolymer lithography: periodic arrays of 1011 holes in 1 square centimeter," Science, vol. 276, no. 5317, pp. 1401-1404, 1997.

[5] C. J. Hawker and T. P. Russell, "Block copolymer lithography: merging "bottom-up" with "top-down" processes," $M R S$ Bulletin, vol. 30, no. 12, pp. 952-966, 2005.

[6] J. Bang, U. Jeong, D. Y. Ryu, T. P. Russell, and C. J. Hawker, "Block copolymer lithography: translation of molecular level control to nanoscale patterns," Advanced Materials, vol. 21, no. 47, pp. 4769-4792, 2009.

[7] A. V. Ruzette and L. Leibler, "Block copolymers in tomorrow's plastics," Nature Materials, vol. 4, no. 1, pp. 19-31, 2005.

[8] A. S. Abd-El-Aziz and I. Manners, Frontiers in Transition Metal-Containing Polymers, Wiley-Interscience, Hoboken, NJ, USA, 2007.

[9] I. Manners, Synthetic Metal-Containing Polymers, VCH, Weinheim, Germany, 2004.

[10] D. Wohrle and A. D. Pomogailo, Metal Complexes and Metals in Macromolecules: Synthesis, Structure and Properties, WileyVCH, Weinheim, Germany, 2003.

[11] C. E. Carraher, A. S. Abd-El-Aziz, C. Pittman, J. Sheats, and M. Zeldin, A Half Century of Metal and Metalloid Containing Polymers, Wiley, New York, NY, USA, 2003.

[12] M. Rehahn, "Organic-inorganic hybrid polymers," in Synthesis of Polymers: A Volume of the Materials Science and Technology Series, A. D. Schluter, Ed., Wiley-VCH, Weinheim, Germany, 1999.

[13] P. Nguyen, P. Gómez-Elipe, and L. Manners, "Organometallic polymers with transition metals in the main chain," Chemical Reviews, vol. 99, no. 6, pp. 1515-1548, 1999.

[14] I. Manners, "Polymer science with transition metals and main group elements: towards functional, supramolecular inorganic polymeric materials," Journal of Polymer Science A, vol. 40, no. 2, pp. 179-191, 2002.

[15] W. A. De Heer, A. Châtelain, and D. Ugarte, "A carbon nanotube field-emission electron source," Science, vol. 270, no. 5239, pp. 1179-1180, 1995.

[16] S. J. Tans, A. R. M. Verschueren, and C. Dekker, "Roomtemperature transistor based on a single carbon nanotube," Nature, vol. 393, no. 6680, pp. 49-52, 1998.

[17] D. H. Lee, D. O. Shin, W. J. Lee, and S. O. Kim, "Hierarchically organized carbon nanotube arrays from self-assembled block copolymer nanotemplates," Advanced Materials, vol. 20, no. 13, pp. 2480-2485, 2008.

[18] A. Javey and H. Dai, "Regular arrays of $2 \mathrm{~nm}$ metal nanoparticles for deterministic synthesis of nanomaterials," Journal of the American Chemical Society, vol. 127, no. 34, pp. 1194211943, 2005.

[19] Y. Li, W. Kim, Y. Zhang, M. Rolandi, D. Wang, and H. Dai, "Growth of single-walled carbon nanotubes from discrete catalytic nanoparticles of various sizes," Journal of Physical Chemistry B, vol. 105, no. 46, pp. 11424-11431, 2001.

[20] C. L. Cheung, A. Kurtz, H. Park, and C. M. Lieber, "Diametercontrolled synthesis of carbon nanotubes," Journal of Physical Chemistry B, vol. 106, no. 10, pp. 2429-2433, 2002. 
[21] L. An, J. M. Owens, L. E. McNeil, and J. Liu, "Synthesis of nearly uniform single-walled carbon nanotubes using identical metal-containing molecular nanoclusters as catalysts," Journal of the American Chemical Society, vol. 124, no. 46, pp. 13688-13689, 2002.

[22] J. Q. Lu, T. E. Kopley, N. Moll et al., "High-quality singlewalled carbon nanotubes with small diameter, controlled density, and ordered locations using a polyferrocenylsilane block copolymer catalyst precursor," Chemistry of Materials, vol. 17, no. 9, pp. 2227-2231, 2005.

[23] J. Lu, S. S. Yi, T. Kopley, C. Qian, J. Liu, and E. Gulari, "Fabrication of ordered catalytically active nanoparticles derived from block copolymer micelle templates for controllable synthesis of single-walled carbon nanotubes," Journal of Physical Chemistry B, vol. 110, no. 13, pp. 6655-6660, 2006.

[24] S. Lastella, Y. J. Jung, H. Yang et al., "Density control of singlewalled carbon nanotubes using patterned iron nanoparticle catalysts derived from phase-separated thin films of a polyferrocene block copolymer," Journal of Materials Chemistry, vol. 14, no. 12, pp. 1791-1794, 2004.

[25] K. Temple, K. Kulbaba, K. N. Power-Billard et al., "Spontaneous vertical ordering and pyrolytic formation of nanoscopic ceramic patterns from poly(styrene-b-ferrocenylsilane)," Advanced Materials, vol. 15, no. 4, pp. 297-300, 2003.

[26] C. Hinderling, Y. Keles, T. Stöckli et al., "Organometallic block copolymers as catalyst precursors for templated carbon nanotube growth," Advanced Materials, vol. 16, no. 11, pp. 876-879, 2004.

[27] J. Q. Lu, D. A. Rider, E. Onyegam et al., "Carbon nanotubes with small and tunable diameters from poly(ferrocenylsilane)block-Polysiloxane diblock copolymers," Langmuir, vol. 22, no. 11, pp. 5174-5179, 2006.

[28] T. Hirai, M. Leolukman, C. C. Liu et al., "One-step direct-patterning template utilizing self-assembly of POSScontaining block copolymers," Advanced Materials, vol. 21, no. 43, pp. 4334-4338, 2009.

[29] T. Hirai, M. Leolukman, S. Jin et al., "Hierarchical selfassembled structures from POSS-containing block copolymers synthesized by living anionic polymerization," Macromolecules, vol. 42, no. 22, pp. 8835-8843, 2009.

[30] Y. Ishida, Y. Tada, T. Hirai et al., "Directed self-assembly of cage silsesquioxane containing block copolymers via graphoepitaxy techniques," Journal of Photopolymer Science and Technology, vol. 23, no. 2, pp. 155-159, 2010.

[31] Y. Ishida, T. Hirai, R. Goseki, M. Tokita, M. Kakimoto, and T. Hayakawa, "Synthesis and self-assembly of thermotropic block copolymer with long alkyl tethered cage silsesquioxane in the side chain," Journal of Polymer Science A, vol. 49, no. 12, pp. 2653-2664, 2011.

[32] R. Goseki, T. Hirai, Y. Ishida, M. Kakimoto, and T. Hayakawa, "Rapid and reversible morphology control in thin films of poly(ethylene oxide)-block-POSS containing poly(methacrylate)," Polymer Journal, vol. 44, pp. 658-664, 2012.

[33] Y. Tada, H. Yoshida, Y. Ishida et al., "Directed self-assembly of POSS containing block copolymer on lithographically defined chemical template with morphology control by solvent vapor," Macromolecules, vol. 45, no. 1, pp. 292-304, 2012.

[34] C. U. Pittman, "Anionic homopolymerization of ferrocenylmethyl methacrylate," Journal of Polymer Science Part A, vol. 15, no. 7, pp. 1677-1686, 1977.

[35] T. Higashihara and R. Faust, "Synthesis of novel block copolymers comprised of polyisobutylene and poly(vinylferrocene) segments," Macromolecules, vol. 40, no. 21, pp. 7453-7463, 2007.

[36] F. Yan, T. Higashihara, R. Mosurkal et al., "Self organization and redox behavior of poly(vinylferrocene)-block-poly (isobutylene)-block-poly(vinylferrocene) triblock copolymer," Journal of Macromolecular Science A, vol. 45, no. 11, pp. 911914, 2008.

[37] Y. Yang, Z. Xie, and C. Wu, "Novel synthesis and characterization of side-chain ferrocene-containing polymers," Macromolecules, vol. 35, no. 9, pp. 3426-3432, 2002.

[38] M. Gallei, B. V. K. J. Schmidt, R. Klein, and M. Rehahn, "Defined poly[styrene-block-(ferrocenylmethyl methacrylate)] diblock copolymers via living anionic polymerization," Macromolecular Rapid Communications, vol. 30, no. 17, pp. 1463-1469, 2009.

[39] M. Gallei, S. Tockner, R. Klein, and M. Rehahn, "Silacydobutane-based diblock copolymers with vinylferrocene, ferrocenylmethyl methacrylate, and [1]dimethylsilaferrocenophane," Macromolecular Rapid Communications, vol. 31, no. 9-10, pp. 889-896, 2010.

[40] J. K. Lindsay and C. R. Hauser, "Aminomethylation of ferrocene to form N,N-dimethylaminomethylferrocene and its conversion to the corresponding alcohol and aldehyde," Journal of Organic Chemistry, vol. 22, no. 4, pp. 355-358, 1957. 

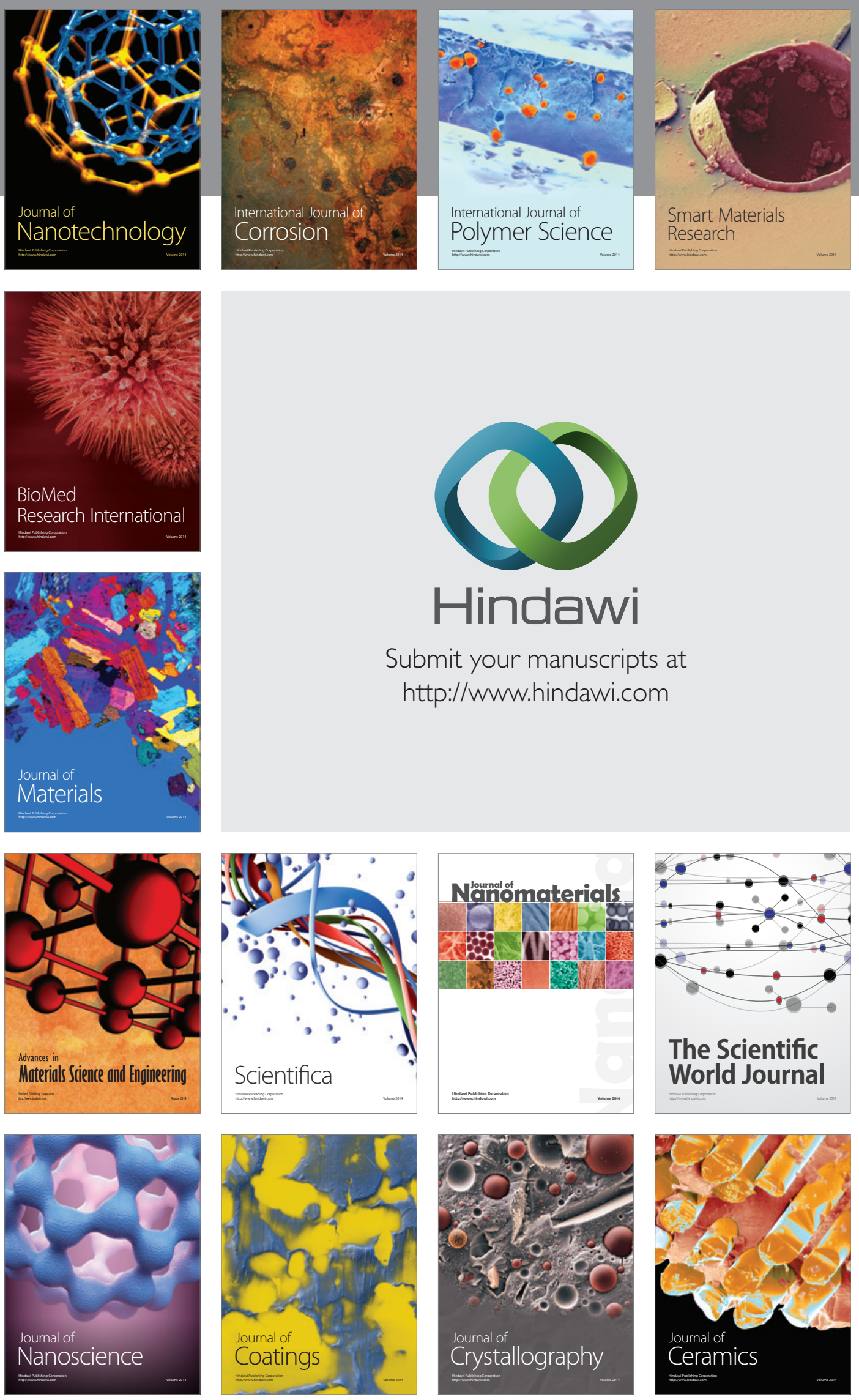

The Scientific World Journal

Submit your manuscripts at

http://www.hindawi.com

\section{World Journal}

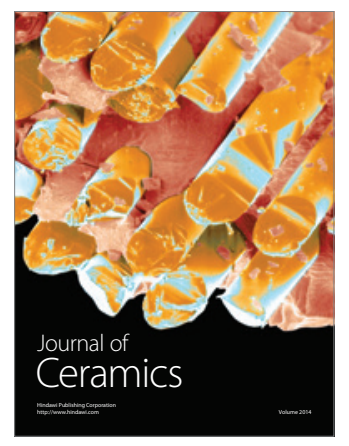

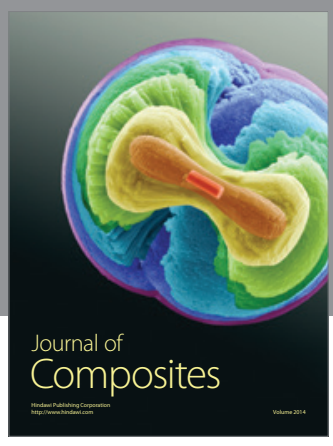
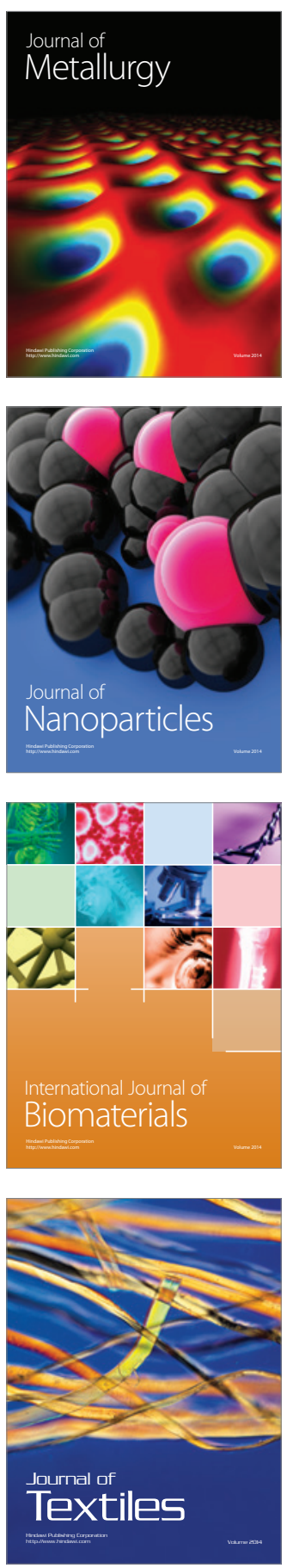